\title{
Mental health in young adults and adolescents - supporting general physicians to provide holistic care
}

\author{
Author: Izabela Jurewicz ${ }^{\mathrm{A}}$
}

In the era of an ageing population, young adults on medical wards are quite rare, as only $12 \%$ of young adults report a long-term illness or disability. However, mental health problems remain prevalent in the younger population. In a recent report, mental health and obesity were listed as the most common problems in young adults. Teams set up specifically for the needs of younger adults, such as early intervention in psychosis services are shown to work better than traditional care and have also proven to be cost effective. On the medical wards, younger patients may elicit strong emotions in staff, who often feel protective and may identify strongly with the young patient's suffering. In order to provide holistic care for young adults, general physicians need to recognise common presentations of mental illness in young adults such as depression, deliberate self-harm, eating disorders and substance misuse. Apart from treating illness, health promotion is particularly important for young adults.

KEYWORDS: Young adults, adolescents, mental health, parity of esteem

\section{Health needs of young adults}

According to the Office for National Statistics, there were around 7.5 million young people aged 16-24 in the UK in 2012, making young adults about $12 \%$ of the general population. The majority of young adults, (about 75\%) are satisfied with their health, a rate that is higher than adults as a whole. Only $12 \%$ of young adults report a long-term illness or disability. Increasing focus is given to this important age of transition from adolescence to adulthood, as the ways in which this psychological and social transition is negotiated may affect current and future well-being. ${ }^{1}$

The pattern of mental ill health across one's lifespan is the mirror image of that seen in physical illness. The peak age of onset of which mental illness occurs is adolescence and early adulthood. ${ }^{2}$ The peak age of onset of physical illness occurs much later in the fifth to sixth decade of life. Clinically it means that younger patients with physical illness are relatively more likely to have co-existing psychological

Author: Aconsultant psychiatrist and honorary clinical lecturer, Cardiff and Vale University Local Health Board, Cardiff, UK difficulties in comparison to older patients. It also means that on medical wards, younger patients are quite rare. Young people may feel at a loss in a medical service which mainly deals with older patients, and their unique needs could easily be overlooked.

Adolescence and early adulthood are times of taking on responsibilities and frequently, rebelling against them. Young adults establish their independence and face the consequences of their actions. For example, adolescents with type 1 diabetes are known to have worse glycaemic control than adults, mainly due to poor meal structure and insulin omitting. ${ }^{3}$ Medication non-compliance may also be a symptom of emerging mental health problems such as eating disorders.

Young adults often rely on their parents to pick up their prescriptions from the chemist and arrange their appointments. They may benefit from being seen in clinic with their parents. In psychiatric practice, involving carers and families is an important aspect of a holistic care plan. Often a history from an informant may add new important information on the symptoms of illness and compliance with medication. For physical practice, it is often the converse, where young people are seen with family members and, recognising the need to interview the young person on their own, as well as with an informant, is part of good practice.

With recent advances in medicine, disability caused by physical ill health has reduced, however the same indices linked to mental ill health remain the same. Analysis of the data collected by the World Health Organisation global burden of disease study over the period of 1990-2010 showed that disability-adjusted life years represented by major physical illness have fallen, while almost every mental health condition had increased its burden of disease in absolute terms. ${ }^{4}$

Mental health conditions make up an increasing proportion of overall disability in society. Treating mental health conditions is 'every doctor's business' and should be given the same priority, a 'parity of esteem', as expected when attending to physical health needs. ${ }^{5}$

Targeting mental health needs of young people works and is cost effective

Emerging evidence of the role of early treatment in order to prevent psychiatric disability has resulted in attempts to make psychiatric services more responsive to the needs of young 
people. ${ }^{6}$ Recent years have seen the development of psychiatric services for 'young people'; a shift from the previous service division of 'children' and 'adults'. In some areas of the country, early intervention teams have been set up which specialise in young people with serious mental illness. These services are known as 'youth services' and cover a varying age range, eg $0-21$ or $0-25$ years, recognising that the previous method of delivering services did not help with treatment at the most vulnerable period in a young adult's life.

Early intervention teams specialise in early detection and offer comprehensive treatment of psychosis. For young people this involves pharmacological, psychological, social, educational and occupational interventions. ${ }^{7}$ A recent systematic review and meta-analysis found that early intervention teams can significantly reduce relapse rates. ${ }^{8}$ Working with patients across the age span of children and young adults (some teams cover ages 12-24 years) cuts across training boundaries for doctors in psychiatry, requiring staff to work closely as a team, with some trained in adolescent psychiatry and some trained in the adult field. Early intervention teams work on the understanding that interventions focused on the specific needs of young people prevent further deterioration and are cost effective in the longer run, resulting in savings to the wider NHS of $\mathfrak{1} 15,862$ per patient over a three-year period. ${ }^{9}$ Supporting education and achieving employment is a focus of young people services, resulting in an increase of employment for people with psychosis from $12 \%$ to $35 \% .^{10}$

Holistic models of care focused on the needs of young people could be used by medical services as the cost benefits include improving treatment adherence, while supporting education and employment are likely to provide similar benefits.

Comorbid mental health problems exacerbate physical health conditions resulting in at least $\mathfrak{£} 8$ billion in additional costs to NHS England. ${ }^{11}$ Potential savings are likely to be higher in younger patients bearing in mind their longer life span.

\section{Experience of young people and staff in acute medical units}

Young adults are a minority in acute medical units (AMU). Their health needs may range from acute presentations with good prognosis to severe, chronic medical problems. Young patients with chronic and severe physical illness are likely to have unmet psychological needs and their medical illness is likely to interfere with education and occupational attainment. Career advisers and alternative educational provision may be helpful in this context. Patients will also potentially need psychological support to help them deal with losses brought on by physical illness.

Sometimes a patient's level of disability is out of proportion to the physical illness and can be linked to 'illness behaviour'. Cognitive behavioural therapy (CBT) can be useful under these circumstances to tackle the patient's underestimation of their coping skills, and their overestimation of 'risk'.

Abnormal illness behaviour in young adults may be a result of frequent admissions as children. This can skew the young adults approach to illness such that their reaction to ill health is 'younger' than their chronological age. Frequent admissions can encourage a dependence on the service, while endangering an under-reliance on self management. Multiple admissions

\section{Box 1. Case vignette: 'Something has to be done'}

Patient 1 is 21 years old and has a history of type 1 diabetes. Since she was handed over by the paediatric team and has had a 'revolving door' pattern of admissions with diabetic emergencies. She would initially ring and say that her blood sugars were high, but seemed unable to act on the advice given by diabetic nurses from the clinic. Once on the ward the patient stops eating despite much encouragement from staff. She presents as a sulky teenager and often communicates very little. All staff are worried about her developing renal complications, especially with such poor food and fluid intake. Medical and nursing staff feel frustrated and rather helpless.

may also create a strong bond with medical and nursing staff, who may become overprotective, furthering dependence in the young patient.

When dealing with young adults with complex needs, medical teams may need to consider support from liaison psychiatric services. It could be helpful to put together a 'team formulation' of the case, taking into account both medical and psychological needs of the patient as well as team/patient dynamics.

Dealing with young people can bring powerful feelings in medical and nursing staff.

Most common are feelings of the following: ${ }^{12}$

$>$ omnipotence ('I must get it right or a whole life will be ruined')

> impotence ('the patient is so vulnerable, but I don't know how to help. We are just going round in circles')

$>$ adolescent feelings (especially when young people question doctor's authority)

> parental feelings (feeling protective and fighting problems rather than respecting their autonomy)

> positive feelings, because the interaction has gone well

> junior medical staff can strongly identify with young people and feel very compassionate.

\section{The most frequent mental health problems in young adults}

Rates of depression, suicidal behaviours, eating disorders and substance abuse have increased steadily among young people in recent decades. The mental health of young adults aged 16-24 years was summarised in the December 2014 report on the well-being of young people. ${ }^{1}$ As a group, young adults were found to be more satisfied with their life than adults as a whole. They were also found to have lower levels of anxiety

Box 2. Junior doctor experience: 'It was difficult'.

As part of my rotation I had to cover the cystic fibrosis unit. Dealing with patients who were my own age was hard. Some patients were having palliative care for their condition at the same age that my life was just starting. I guess I could identify with them more. I found it difficult. 
than older adults. However, the following statistics were reported:

$>$ one in five young adults had symptoms of depression or anxiety

$>2.2 \%$ of $16-24$ year olds in Great Britain experienced a depressive episode

$>6.2 \%$ of $16-24$ year olds have attempted suicide in their lifetime

$>8.9 \%$ of $16-24$ year olds have self-harmed in their lifetime

> 194 15-19 year olds and 427 20-24 year olds committed suicide in 2011

\section{Depression and suicidal behaviour in young adults}

Suicide is a leading cause of death in people aged 15-24 years. For each completed suicide in the young there are about 100 suicide attempts reported. ${ }^{13}$

Deliberate self-harm and parasuicidal behaviours are common psychiatric presentations of young people on medical wards. However, there will be some areas (for example poisons units) that have particular expertise in helping young people who present with overdoses requiring medical treatment.

A 2009 review found that patients felt health workers were only concerned with their physical health, leaving mental health aside. ${ }^{14}$ Working with people who self-harm provides medical trainees with experience in talking to young people in distress, and allows the trainee to develop a compassionate and non-judgemental approach. The characteristics of an assessment by healthcare professionals can affect suicide risk identification and response, ${ }^{15}$ with a compassionate approach by far the most useful and potentially life saving, as patients are more likely to disclose their suicidal thoughts. Many hospitals use various risk assessment tools, often recorded electronically. However, suicide is rare and not easily predicted using risk assessment tools. Suicide mitigation measures may include focusing on patient's existing coping mechanisms and formulating a safety plan. ${ }^{16}$

\section{Eating disorders}

Most eating disorders have an onset in adolescence. Anorexia nervosa starts most often at the age of 15 , affecting $0.9 \%$ of females and $0.3 \%$ of males. It is estimated that approximately one-third of cases never seek help, hence a high index of suspicion is important. ${ }^{17}$

Rates of bulimia nervosa are rising steadily, affecting $1.5 \%$ of women and $0.5 \%$ of men. Patients with bulimia use compensatory behaviours to counteract episodes of eating out of control (binging). Some induce vomiting, while others may use laxatives, enemas, diuretics or stimulants, such as diet pills or amphetamine.

Young patients with diabetes presenting with frequent hypoglycaemia should be screened for presence of an eating disorder. Omitting insulin, leading to a loss of fluid perceived as weight loss is a recognised form of compensatory behaviour in patients with type 1 diabetes and bulimia.

Anorexia nervosa has the highest mortality rate of any psychiatric condition. Approximately half of deaths are due to suicide and the other half mostly due to cardiac arrhythmias.
Binge eating disorder is the most common eating disorder, affecting $3.5 \%$ of women and $2 \%$ of men; it is present in about one-third of cases of obesity. ${ }^{18}$ Look for a history of binges, especially in reaction to emotional events and accompanying feelings of guilt.

\section{Substance misuse}

Drugs used by young adults mainly include amphetamines, anabolic steroids, club drugs, cocaine, heroin, inhalants and prescription drugs. Recent statistics show that about $40 \%$ of young adults aged 16-24 years have used illicit substances at least once; these figures have remained stable over the past ten years. One in five young people reported use of illicit drugs within the previous year and one in ten within the previous month. Cannabis was used most often; its use has slowly declined throughout most of the decade. Young adults (16-24 year olds) are a vulnerable group for illicit substance use, as frequent drug use was reported as more than twice as high (7.3\%) compared with $16-59$ year olds $(3.35 \%){ }^{19}$

The majority of young people accessing specialist drug and alcohol interventions have problems with alcohol (37\%) and cannabis $(53 \%)$, requiring psychosocial, harm reduction and family interventions, rather than treatment for addiction. By contrast, the majority of adults accessing specialist drug and alcohol interventions require treatment for addiction. ${ }^{20}$ Most young people engage with specialist drug and alcohol interventions for a short period of time, often weeks, and then continue support from third-sector organisations. Young people and their needs differ from adults, for example drug use can pose a greater hazard to the developing brain.

\section{Health promotion for young adults}

In psychiatry in recent years there has been more emphasis on the medical needs of people with mental health problems. As a group, patients with serious mental illness are more likely to smoke, ${ }^{21}$ have diabetes and be overweight. Psychiatric medications, which are of crucial importance to their mental health, can have medical side effects, such as metabolic syndrome and weight gain. ${ }^{22}$

Health promotion is important for all patients with mental ill health, but particularly so for young adults due to the early onset of mental ill health and relatively long exposure to risk.

\section{Concluding thoughts}

Young adults as a group enjoy relatively good health. Mental health problems and obesity are the most common health complaints. In response to the mental health needs of young people, there has been a movement to develop psychiatric services specifically for young adults. If there is similar development for medical needs of young people, there needs to be a recognition of their psychological as well as physical needs.

\section{References}

1 Office for National Statistics. Measuring national well-beingexploring the wellbeing of young people in the UK, 2014. Newport: ONS, 2014. 
2 Kessler RC, Berglund P, Demler O et al. Lifetime prevalence and age-of-onset distributions of DSM IV disorders in the National Co-morbidity Survey Replication. Arch Gen Psychiatry 2005;62:595-602.

3 Hoffman RP. Adolescent adherence in type 1 diabetes. Compr Ther 2002;28:128-33.

4 Murray CJL, Richards MA, Newton JN et al. UK health performance: findings of the Global Burden of Disease Study 2010. Lancet 2013;381:997-1020.

5 Bailey S. Why 'parity of esteem' for mental health is every hospital doctor's concern. Br J Hosp Med (Lond) 2014;75:277-80.

6 Marshall M, Lewis S, Lockwood A et al. Association between duration of untreated psychosis and outcome in cohorts of first-episode patients: a systematic review. Arch Gen Psychiatry 2005;62:975-83.

7 National Institute for Health and Care Excellence. Schizophrenia: Core interventions in the treatment and management of schizophrenia in adults in primary and secondary care. CG82. London: NICE, 2009.

8 Alvarez-Jimenez M, Parker AG, Hetrick SE et al. Preventing the second episode: a systematic review and meta-analysis of psychosocial and pharmacological trials in first episode psychosis. Schizophr Bull 2011;37:619-30.

9 Andrews A, Knapp M, McCrone P, Parsonage M, Trachtenberg M. Effective interventions in schizophrenia: the economic case. 2012. Available online at www.lse.ac.uk/LSEHealthAndSocialCare/pdf/ LSE-economic-report-FINAL-12-Nov.pdf [Accessed 6 January 2015].

10 McCrone P, Park AL, Knapp M. Economic evaluation of early intervention services: phase IV report. PSSRU Discussion Paper 2475. London: PSSRU, November 2010.

11 Naylor C, Galea A, Parsonage M et al. Long-term conditions and mental health: the cost of co-morbidities. London: The King's Fund, February 2012. Available online at www.kingsfund.org.uk/sites/ files/kf/field/field_publication_file/long-term-conditions-mentalhealth-cost-comorbidities-naylor-feb12.pdf [Accessed 6 January 2015].

12 Donovan C, Suckling H, Walker Z. Difficult consultations with adolescents. London: Radcliffe Medical Press, 2004.
13 Andrews G, Jenkins R. Management of mental disorders. World Health Organization Collaborating Centre for Mental Health and Substance Abuse, 2000.

14 Taylor TL, Hawthorn K, Fortune S et al. Attitudes towards clinical services among people, who self-harm: systematic review. $\mathrm{Br} \mathrm{J}$ Psychiatry 2009;194:104-10.

15 Cole-King A, Green G, Gask L et al. Suicide mitigation: a compassionate approach to suicide prevention. Adv Psychiatr Treat 2013;19:276-83.

16 Cole-King Parker V, Williams $\mathrm{H}$ et al. Suicide prevention: are we doing enough? Adv Psychiatr Treat 2013;19:284-91.

17 Birmingham C, Treasure J. Medical management of eating dsorders. Cambridge: Cambridge University Press, 2010.

18 Hudson J, Hiripi E, Pope $\mathrm{H}$ et al. The Prevalence and correlates of eating disorders in the national comorbidity survey replication. Biol Psychiatry 2007;61:348-58.

19 The Health and Social Care Information Centre. Statistics on drug misuse: England 2011. Leeds: The Health and Social Care Information Centre, 2011. Available online at www.drugscope.org. uk/Resources/Drugscope/Documents/PDF/Good\%20Practice/ Statistics_on_Drug_Misuse_England_2011v3.pdf [Accessed 6 January 2015].

20 National Treatment Agency for Substance Misuse. Healthcare professionals and partners: young people. Available online at www.nta. nhs.uk/young-people.aspx [Accessed 6 January 2015].

21 McManus S, Meltzer H, Campion J. Cigarette smoking and mental health in England: data from the adult psychiatric morbidity survey 2007 (updated 2010). Available online at www.natcen.ac.uk/ media/21994/smoking-mental-health.pdf [Accessed 6 January 2015].

22 Kahn RS, Fleishhacker WW, Boter H et al. Effectiveness of antipsychotic drugs in first-episode schizophrenia and schizophreniform disorder: an open, randomised trial. Lancet 2008;371:1085-97.

Address for correspondence: Dr I Jurewicz, Pentywn CMHT, Brynheulog Rd, Cardiff CF23 7JD, UK.

Email: isabella.jurewicz2@wales.nhs.uk

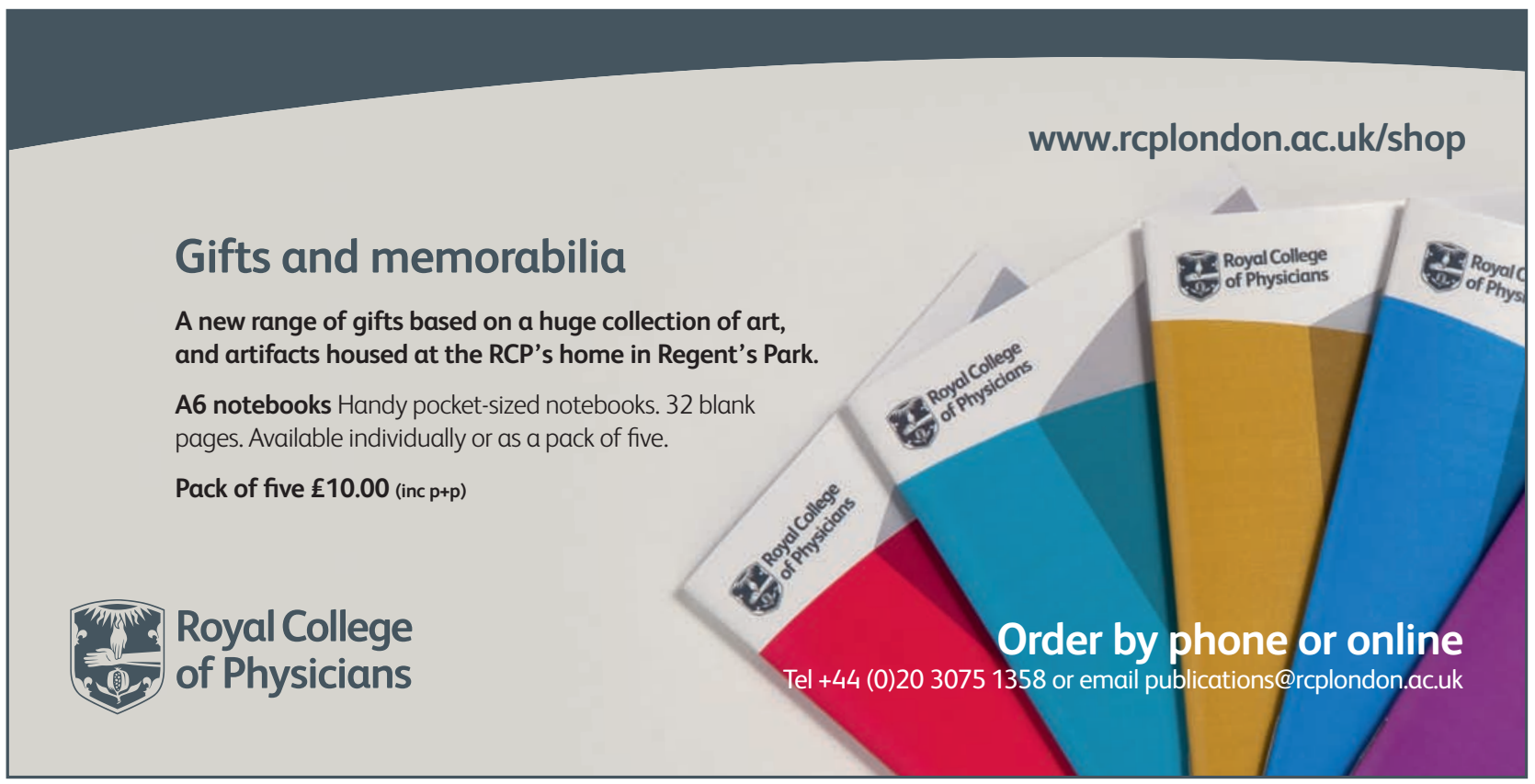

